\title{
AMBIGUITY IN DIAGNOSING CHONDROID CHORDOMA-A CASE REPORT
}

Swarnagowri B. N¹, R. Shubha Sangeetha², Ashwini M. C³, Krishna Kishor ${ }^{4}$

\section{HOW TO CITE THIS ARTICLE:}

Swarnagowri B. N, R. Shubha Sangeetha, Ashwini M. C, Krishna Kishor. "Ambiguity in Diagnosing Chondroid Chordoma-A Case Report”. Journal of Evolution of Medical and Dental Sciences 2014; Vol. 3, Issue 37, August 21; Page: 9553-9555, DOI: 10.14260/jemds/2014/3235

\begin{abstract}
Chondroid chordoma" is a controversial and confusing entity, a biphasic malignant neoplasm possessing elements of both chordoma and cartilaginous tissue. The annual incidence of chordoma is approximately one in one million. Chondroid chordoma is a subtype of chordoma possessing elements of both chordoma and cartilaginous tissue with better prognosis than classic (non chondroid) chordomas. We have come across a case of Chondroid Chordoma in a 55 year old male. Our report features particularly a rare entity, chondroid chordoma, with an exceptional localization to the nasal septum. Chondroid Chordomas are likely to recur and hence diagnostically important to institute effective treatment.
\end{abstract}

KEYWORDS: Chordoma, embryonal, germ cell.

INTRODUCTION: Chordomas were first described by Virchow in 1857 as tumors made up of vacuolated or 'physaliferous' cells derived from rests of embryonic notochord along the midline central nervous system axis.[1]

"Chondroid chordoma" is a controversial and confusing entity that was described by Heffel finger and colleagues as a biphasic malignant neoplasm possessing elements of both chordoma and cartilaginous tissue. ${ }^{[2]}$ Chordoma are slow-growing, low-grade malignancies at $6^{\text {th }}$ decade, however, presentation with skull base tumors may occur at a younger age and has been reported in children and adolescents. Spheno-occipital chordomas may present with a nasal, paranasal, or nasopharyngeal mass. ${ }^{[2]}$

CASE REPORT: We had a case of 55yr. old male with h/o nasal obstruction with a mass in the right nasal cavity. The specimen was a grey white soft tissue mass and measured $3.5 \times 3 \times 1.5 \mathrm{cms}$ in dimension. The external surface appeared mucoid with lobulations. Cut section revealed grey white areas with mucoid areas [Fig. 1].

MICROSCOPY: Showed a tumor tissue with a lobulated appearance, with the fibrous septae and mucoid intercellular tissue separating the lobules. Some of the tumor cells (physaliferous) were extremely large, with vacuolated cytoplasm and prominent vesicular nucleus; other tumor cells were small, with inconspicuous nuclei and no visible nucleoli. Mitotic figures were scanty or absent. Areas of cartilaginous differentiation were present. [Fig. 2] Immunohistochemical staining for S-100 protein, Cytokeratin and EMA were done. The tumor showed positivity for CK and EMA. It was negative for S-100 protein. [Fig. 3, 4]. So the diagnosis was based on the Immunohistochemistry along with the histomorphological features.

DISCUSSION: Chondroid chordomas are thought to be derived from the notochord. The notochord is a transient structure of embryogenesis, which arises as a pouch from the mesoderm during 
gastrulation. It defines the primitive axis of the embryo, conditions its elongation, and the formation of the neural tube. In higher vertebrates, it regresses completely throughout the column except in the nucleus pulposus. This process explains why chordomas are located along the axial skeleton (from the sacrum to the sphenoidal clivus).[3]

They arise from the sacrum (50\%-60\% of cases), from spheno-occipital/nasal $(25 \%-35 \%$ of cases), from the cervical vertebrae (10\% of cases), and from the thoraco lumbar vertebrae $5 \%$ of cases).[2] Grossly, chordoma is gelatinous and soft and contains areas of haemorrhage.

Microscopically, it closely resembles normal notochord tissue in its different stages of development.

It grows in cell cords and lobules separated by a variable amount of mucoid intercellular tissue and by fibrous septa. Some of the tumor cells (physaliferous) are extremely large, with vacuolated cytoplasm and prominent vesicular nucleus; some of the cytoplasmic vacuoles contain glycogen. Other tumor cells are small, with inconspicuous nuclei and no visible nucleoli. Mitotic figures are scanty or absent. Areas of cartilage and bone may be present.

The microscopic differential diagnosis includes chondrosarcoma, signet cell adenocarcinoma of the rectum, myxopapillary ependymoma, and chordoid meningioma.[2] There are three histological variants of chordoma: classical or ("conventional") chondroid and dedifferentiated.[4]

Immuno histochemically, chordoma shows reactivity for S-100 protein, keratin, epithelial membrane antigen (EMA), In contrast, D2-40 positive, EMA, pan CK \&GFAP negative in chondrosarcoma. GFAP positive, EMA negative in myxopapillary ependymoma. EMA positive and pan CK negative in chordoid meningioma. Huse JT et al showed that D2-40 which is a monoclonal antibody, behaves as a chondroid marker differentiating true chondroid neoplasms from chordoma. ${ }^{[5]}$

CONCLUSION: Our report features particularly a rare tumor chondroid chordoma, with an exceptional localization to the nasal septum. This case illustrates the difficulty in diagnosing chondroid chordoma until a strong suspicion is considered. Chondroid Chordomas are likely to recur and result in treatment failure. Awareness of this rare tumour will avoid misdiagnosis and improve the prognosis.

ACKNOWLEDGEMENT-We are grateful to Dr. Gayathri , ENT Surgeon, Dr. B.R. Ambedkar Medical College, for providing us this case

\section{REFERENCES:}

1. Chordoma review of clinicoradiological features and factors affecting survival. Australas Radiol 2001, 45: 427-434. Am J Clin Pathol. 1995 Mar; 103 (3): 271-9.

2. Chondroid chordoma. A hyalinized chordoma without cartilaginous differentiation.

3. Jeffrey PB'1, Biava CG, Davis RL. Am J Clin Pathol. 1995 Mar; 103 (3): 271-9. J. R. Salisbury, "The pathology of the human notochord, "Journal of Pathology, 1993; 171 (4): 253-255.

4. Chugh R, Tawbi H, Lucas DR, Biermann JS, Schuetze SM, Baker LH (November 2007). "Chordoma: the nonsarcoma primary bone tumor". Oncologist 12 (11): 1344-50.

Doi: 10.1634/theoncologist.12-11-1344. PMID 18055855.

5. Huse JT, Pasha TL, Zhang PJ-; D2-40 functions as an effective chondroid marker distinguishing 
true chondroid tumors from chordoma.; Acta Neuropathol. 2007; 113(1): 87-94

6. Hong Jiang W, Ping Zhao S, Hai Xie Z, Zhang H, Zhang J, Yun Xiao J: Endoscopic resection of chordomas in different clival regions.Acta Otolaryngol 2009, 129:71-83.

7. Colli B, Al-Mefty 0: Chordomas of the craniocervical junction: follow-up review and prognostic factors. J Neurosurg 2001, 95:933-943.

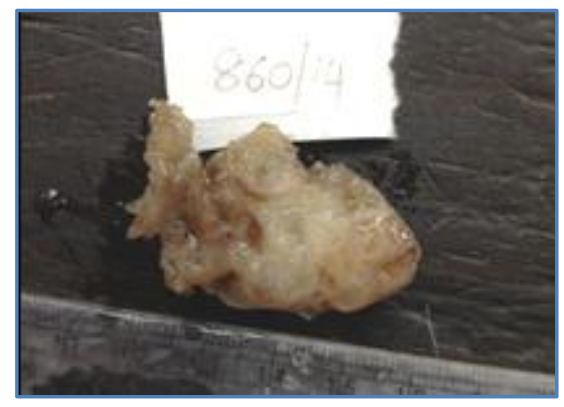

Fig. 1: Gross appearance: Mucoid and cartilaginous areas are seen.

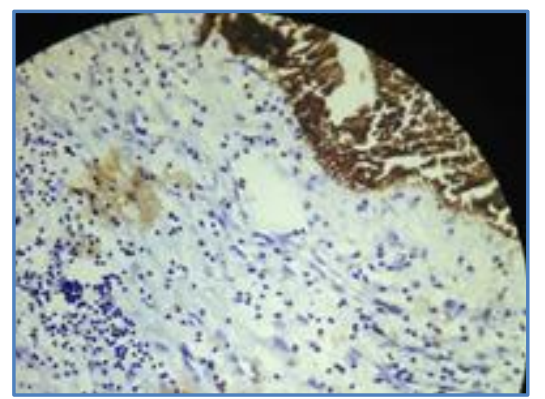

Fig. 3: Focal CK positivity

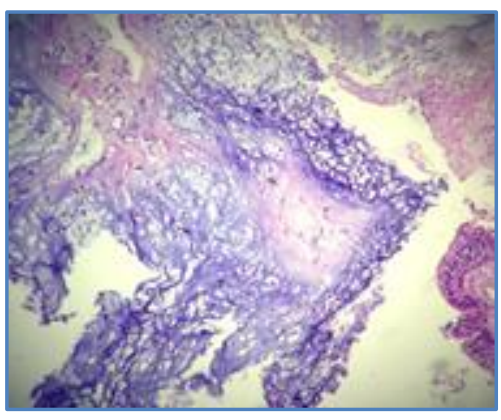

Fig. 2: (10x) H \& E. Physaliferous cells with chondroid differentiation.

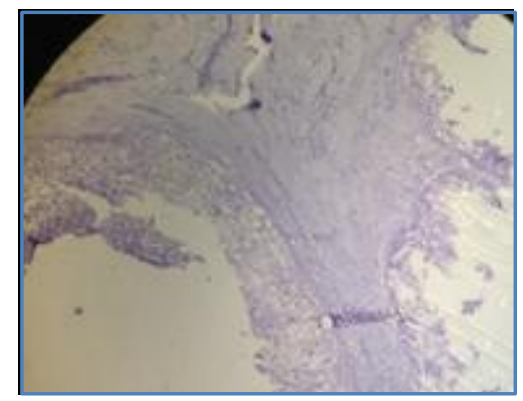

Fig. 4: S-100 Protein is negative

\section{AUTHORS:}

1. Swarnagowri B. N.

2. R. Shubha Sangeetha

3. Ashwini M. C.

4. Krishna Kishor

\section{PARTICULARS OF CONTRIBUTORS:}

1. Professor, Department of Pathology, Dr. B. R. Ambedkar Medical College, Bangalore.

2. Assistant Professor, Department of Pathology, Dr. B. R. Ambedkar Medical College, Bangalore.

3. Post Graduate Student, Department of Pathology, Dr. B. R. Ambedkar Medical College, Bangalore.

4. Post Graduate Student, Department of Pathology, Dr. B. R. Ambedkar Medical College, Bangalore.

\section{NAME ADDRESS EMAIL ID OF THE CORRESPONDING AUTHOR:}

Dr. Swarnagowri B. N,

No. $21,6^{\text {th }}$ Cross,

Vasanthnagar,

Bangalore.

Email: swarnagowri@ymail.com

Date of Submission: 06/08/2014.

Date of Peer Review: 07/08/2014.

Date of Acceptance: 18/08/2014.

Date of Publishing: 19/08/2014. 